Revista Brasileira de Cartografia

ISSN 1808-0936 | https://doi.org/10.14393/revbrascartogr

Sociedade Brasileira de Cartografia, Geodésia, Fotogrametria e Sensoriamento Remoto

\title{
Análise Temporal de Ilhas de Calor Através da Temperatura de Superfície e do Índice de Vegetação em Recife-PE, Brasil
}

\author{
Temporal Analysis of Heat Islands Through Surface Temperature and Vegetation Index in \\ Recife-PE, Brazil
}

Raquel Arcoverde Vila Nova ${ }^{1}$, Rodrigo Mikosz Gonçalves ${ }^{2}$ e Fábio Vinícius Marley Santos Lima ${ }^{3}$

1 Universidade Federal de Pernambuco, Departamento de Engenharia Cartográfica, Recife, Brasil. raquel.vilanova@ufpe.br. ORCID: https://orcid.org/0000-0003-2055-0387

2 Universidade Federal de Pernambuco, Departamento de Engenharia Cartográfica, Recife, Brasil. rodrigo.mikosz@ufpe.br. ORCID: https://orcid.org/0000-0002-5066-1910

3 Universidade Federal de Pernambuco, Departamento de Engenharia Cartográfica, Recife, Brasil. fabio.vinicius@ufpe.br. ORCID: https://orcid.org/0000-0001-6799-55733

Resumo: Entre os fatores antrópicos que atuam na alta vulnerabilidade para formação de ilhas de calor estão a relação com a densidade populacional e as mudanças no uso do solo. Neste estudo de caso destaca-se que a cidade do Recife possuí uma alta densidade populacional. O objetivo geral desta pesquisa é analisar as variações do índice de vegetação e a temperatura da superfície para identificar a influência dos mesmos na formação de ilhas de calor. Como materiais são utilizadas imagens multiespectrais temporais (Landsat 5-TM e Landsat 8-OLI) abrangendo os anos de 1989 a 2019. Os principais resultados encontrados são: (i) o ano de 2019 com temperaturas mais elevadas, chegando a regiões com $37^{\circ} \mathrm{C}$; (ii) em 1989 os valores mais altos foram de $32^{\circ} \mathrm{C}$; (iii) em termos de área, a cidade do Recife sofreu um crescimento de $34 \%$ para temperaturas acima de $33^{\circ} \mathrm{C}$ e obteve um decréscimo de $44 \%$ considerando temperaturas mais amenas; (iv) os valores da cobertura vegetal sofreram mudanças representativas como o crescimento de $15 \%$ no índice de solo exposto, e a redução de $18 \%$ do índice de vegetação média; (v) as correlações de Spearman indicam que existem uma forte relação inversamente proporcional entre os dois parâmetros avaliados (temperatura e índice de vegetação), com valores de -0,72 para 1989 e -0,59 para 2019. Por fim, foi possível detectar o processo de formação das ilhas de calor, bem como as ilhas de frescor, observando um aumento na temperatura superficial principalmente onde o processo de urbanização se intensificou no decorrer do tempo.

Palavras-chave: Ilhas de Calor Urbana. Temperatura da Superfície. NDVI. Sensoriamento Remoto. Landsat.

\begin{abstract}
Among the anthropic factors that act in the high vulnerability of heat islands formation are the relationship with population density and changes in land use. In this case study, it is highlighted that the city of Recife has a highdensity population and considered the fourth Brazilian capital with the largest in the country. The general objective of this research is to analyze the variations in the vegetation index and the surface temperature to identify their influence on the formation of heat islands. Temporal multispectral images (Landsat 5-TM and Landsat 8-OLI) covering the years 1989 to 2019 are used as materials. The main results found are: (i) the year of 2019 with higher temperatures, reaching regions with $37^{\circ} \mathrm{C}$; (ii) in 1989 the highest values were $32^{\circ} \mathrm{C}$; (iii) in terms of area, the city of Recife experienced a $34 \%$ increase of temperatures above $33^{\circ} \mathrm{C}$ and obtained a decrease of $44 \%$ considering milder temperatures; (iv) the vegetation cover values underwent significant changes, such as the $15 \%$ growth in the exposed soil index, and the $18 \%$ reduction in the average vegetation index; (v) Spearman's correlations indicate that there is a strong inversely proportional relationship between the two parameters evaluated (temperature and vegetation index), with values of -0.72 for 1989 and -0.59 for 2019 . Finally, it was possible to detect the formation of heat islands, as well as freshness islands, observing an increasement of surface temperature especially where the urbanization process has intensified over time.
\end{abstract}

Keywords: Urban Heat Islands. Surface Temperature. NDVI. Remote Sensing. Landsat.

\section{INTRODUÇÃO}

Ao longo das últimas décadas os centros urbanos de diversos municípios brasileiros e suas redondezas 
vêm apresentando mudanças em relação ao uso e ocupação do solo. Diversos casos evidenciam as consequências negativas do aumento de temperatura para a sociedade e ao meio ambiente, apresentando em alguns casos desconforto térmico e doenças ligadas ao aparelho respiratório (BARROS; LOMBARDO, 2016; FRANÇA et al., 2015; MOREIRA; NÓBREGA, 2011). Entre as perdas ambientais ocasionadas pelo crescimento urbano que afetam a dinâmica das espécies animais e vegetais está a degradação da vegetação, muitas vezes relacionada com processos expressivos de urbanização, o que afeta por exemplo na impermeabilização do solo. Esta pode ser considerada com um dos parâmetros que interferem no balanço de energia entre a superfície e a atmosfera e que pode contribuir para influenciar na variabilidade do clima de uma cidade (NÓBREGA; LEMOS, 2011; OKE, 1973).

Segundo Moreira (2014) a alteração do clima local pode ser provocada pelo surgimento de um gradiente horizontal urbano de temperatura, sendo este ocasionado pela relação dos fatores que alteram a cobertura e dinâmica do solo como por exemplo: a diminuição no percentual de vegetação, a impermeabilização desordenada do solo, o aumento da rugosidade da superfície, a diminuição do fluxo de calor latente, o aumento do fluxo de calor sensível, entre outros. Um indicador das alterações do clima local é a identificação e espacialização das chamadas Ilhas de Calor Urbanas (ICU).

Arya (2001) define o termo ICU como sendo a relação entre aumento da temperatura da superfície e do ar sobre uma área urbana quando comparadas às zonas menos urbanizadas em sua vizinhança. Portanto, as Ilhas de Calor Urbanas ocorrem, geralmente, no centro das cidades onde as construções se configuram de maneira aglomerada e compacta, como os corredores de prédios e ruas estreitas nos grandes centros, que são chamados de Cânions Urbanos (ARNFIELD, 2003; LO; QUATTROCHI, 2003; NÓBREGA; SANTOS; MOREIRA, 2016; SOUZA, 2008).

O fenômeno ICU vem sendo estudado desde o século XX, quando Manley (1958) o denominou assim. Por ser um assunto de bastante relevância para o desenvolvimento e bem-estar nos centros urbanos, diversos pesquisadores têm se dedicado a encontrar soluções para identificar tal fenômeno. Este é um problema que vem sendo discutido tanto a nível nacional como internacionalmente, onde pesquisas têm sido aplicadas em estudos de caso relatados em regiões brasileiras, como por exemplo: (a) Belém, no estado do Pará (BEZERRA; MORAES; SOARES, 2018) (b) cidades do estado de São Paulo, tais como Presidente Prudente (AMORIM; DUBREUIL; CARDOSO, 2015), Rancharia (TEIXEIRA; AMORIM; DUBREUIL, 2015), e a área urbana da Ilha Solteira (COSTA; SILVA; PERES, 2010); (c) Londrina, no estado do Paraná (GAMARRA; CORRÊA; TARGINO, 2014); (d) região metropolitana do Rio de Janeiro (SENA; FRANÇA; PERES, 2014); (e) Nova Andradina, no estado do Mato Grosso do Sul (LIMA; AMORIM, 2011); como em várias regiões pelo mundo, (f) Hong Kong (LIU; ZHANG, 2011); (g) 38 das cidades mais populosas dos Estados Unidos (IMHOFF et al., 2010), Phoenix (SUN et al., 2009) e Minnesota (YUAN; BAUER, 2007); (h) cidade de Atenas, na Grécia (STATHOPOULOU; CARTALIS, 2009), entre outras.

$\mathrm{Na}$ literatura nacional considerando a cidade do Recife, muitas pesquisas vêm sendo desenvolvidas no que diz respeito ao fenômeno ICU e suas consequências para a população recifense. Alguns destes trabalhos fazem uma abordagem específica considerando a mesorregião da cidade, não envolvendo assim um estudo que identifique o fenômeno em todo Recife. França et al. (2015) trazem um estudo sobre o desconforto térmico causado pela formação da ICU no bairro da Boa Vista através de uma análise temporal; Moreira e Galvíncio (2007) obtiveram resultados no estudo do fenômeno para uma região de grande importância para a cidade, a área do aeroporto dos Guararapes, através do uso de imagens oriundas do Landsat 7 para o ano de 2002; Moreira e Nóbrega (2011) também voltaram seus estudos para a área do aeroporto, porém utilizaram uma série temporal de imagens do Landsat 5 para os anos de 1984 e 2007. Outros trabalhos que abrangem toda a área da cidade do Recife não fizeram uso do sensoriamento remoto para tal, como é o caso dos estudos de Nóbrega, Santos e Moreira (2016) e Nóbrega e Lemos (2011).

Uma ferramenta que auxilia na identificação das Ilhas de Calor é o uso de imagens de satélite, através da relação entre a radiação eletromagnética emitida e a refletida dos alvos, onde é possível extrair e identificar parâmetros que influenciam diretamente na temperatura da área observada (CHEN et al., 2006; GALLO et al., 1995; PENG et al., 2012).

Frente a isso, o presente trabalho tem como objetivos: (i) utilizar imagens de satélites temporais para o período de 1989 a 2019 para analisar quantitativamente a variação espaço-temporal dos parâmetros físicos 
NDVI e temperatura da superfície; e (ii) identificar a formação e espacialização do fenômeno de Ilhas de Calor Urbana (ICU), ambos objetivos aplicados à cidade do Recife, no estado de Pernambuco.

\section{2 ÁREA DE ESTUDO}

A área de estudo (Figura 1) deste trabalho se refere a cidade do Recife, capital do estado de Pernambuco, com uma área de aproximadamente $218 \mathrm{~km}^{2}$, com altitude média variando entre 4 a 10 metros. Sua população foi estimada pelo IBGE (2018) em 1.637 .834 habitantes, ocupando a posição de $9^{\circ}$ município mais populoso do país. A Figura 1 apresenta em (a) a ampliação do recorte contendo a área de estudo em; (b) o mapa do Brasil com destaque para o estado de Pernambuco e em (c) A cidade do Recife localizado no estado de Pernambuco.

Figura 1 - Esboço da localização da área de estudo, onde (a) um recorte da área de estudo, cidade do Recife; (b) representa o estado de Pernambuco, localizado no nordeste do Brasil; (c) destaque para Recife no estado de

Pernambuco.

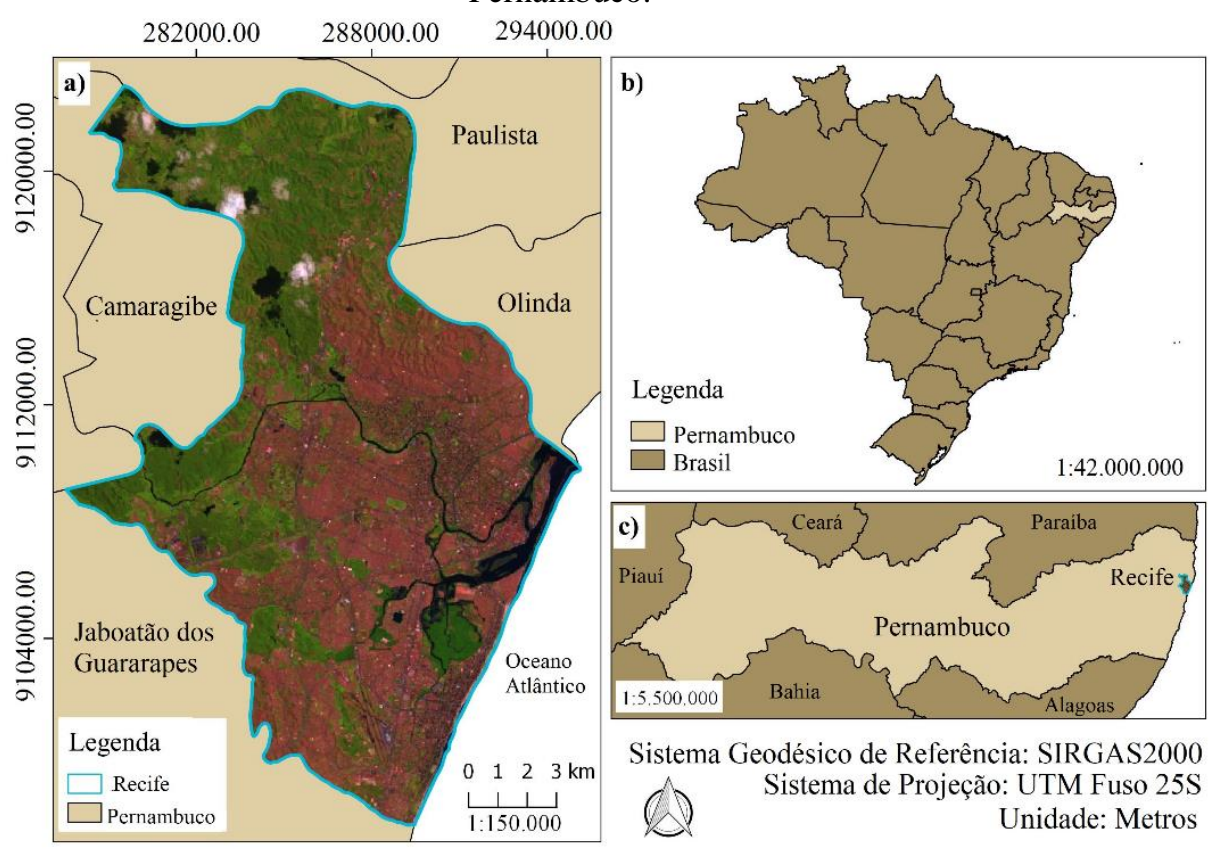

Fonte: Os autores (2021).

O clima da região, segundo a classificação de Köppen-Geiger (2004), é tropical quente e úmido, com a média de temperatura anual de $25,4^{\circ} \mathrm{C}$ e amplitude de $2,8^{\circ} \mathrm{C}$, com uma média anual de umidade relativa do ar de $84 \%$. A cidade possui um regime pluviométrico que se divide em dois períodos diferentes: uma estação seca ou com pouca chuva, que se estende de setembro a fevereiro, e uma estação chuvosa, que ocorre entre março e agosto, com índice médio anual pluviométrico acima de 1.600mm (SECTMA, 2006).

\section{MATERIAL E MÉTODOS}

\subsection{Material}

Os materiais utilizados são imagens digitais gratuitas geradas pelo sensor Thematic Mapper - TM do satélite Landsat 5, para os anos de 1989, 1994, 2005 e 2010, e pelos sensores Operacional Land Imager - OLI e Thermal Infrared Sensor - TIRS a bordo do Landsat 8 para os anos de 2013 e 2019. As bandas utilizadas no processamento foram as do vermelho, infravermelho próximo e a banda do infravermelho termal, bem como o modelo SEBAL (Surface Energy Balance Algorithms for Land) - (Algoritmo de balanço de energia superficial para a Terra) e o software livre QGIS na versão 2.14.18.

As imagens de satélite se referem a órbita 214, para os pontos que abrangem a área de estudo (65 e 66), considerando os anos de 1989, 1994, 2005, 2010, 2013 e 2019. As imagens foram obtidas em um período 
seco e com pouca precipitação (MOREIRA, 2014; SANTOS, 2011), priorizando imagens com o menor recobrimento de nuvens na área de estudo. Todas as imagens foram obtidas, de forma gratuita, através servidor online do Serviço Geológico Americano (GLOVIS USGS) <https://glovis.usgs.gov/> em formato 'geotiff'. A Tabela 1 apresenta um resumo dos materiais utilizados na pesquisa contendo a fonte, data, resolução espacial e uso das imagens.

Tabela 1 - Materiais utilizados.

\begin{tabular}{c|c|c|cc}
\hline Fonte & Data & Resolução espacial $(\mathbf{m})$ & Uso \\
\hline \multirow{3}{*}{ Landsat 5 } & $28 / 09 / 1989$ & Banda do vermelho $=30$ & a) & Temperatura da \\
& $29 / 11 / 1994$ & Banda do infravermelho $=30$ & superfície; \\
& $08 / 09 / 2005$ & Banda termal $=120$ & b) & Modelo SEBAL; \\
& $06 / 09 / 2010$ & & c) & NDVI. \\
& $28 / 07 / 2013$ & Banda do vermelho $=30$ & \\
\hline
\end{tabular}

Fonte: Os autores (2021).

Os dados do Landsat 5 e 8 contam com uma resolução temporal de 16 dias e uma resolução espacial de 30m para todas as bandas, com exceção da banda termal, onde no Landsat 5 (banda 6) é de 120m e, no Landsat 8 (banda 10) é de 100m; a resolução radiométrica para o sensor TM é de 8 bits, para o sensor OLI é de 16 bits e, para o TIRS é de 12 bits, sendo este último responsável para banda termal do Landsat 8. As imagens termais são reamostradas para uma resolução de 30m e disponibilizadas pela USGS.

O modelo SEBAL tem como objetivo estimar de forma instantânea as componentes do balanço de energia através do sensoriamento remoto, visando a medição do fluxo da evapotranspiração, que é a medida residual da equação do balanço de energia superficial para um tempo específico, calculado para cada pixel; onde o algoritmo envolve a utilização de imagens de satélite e algumas informações obtidas em estações meteorológicas de superfície (ALLEN; TASUMI; TEREZZA, 2002; BASTIAANSSEN, 1995; MOREIRA et al., 2017). Algumas das vantagens do modelo, apresentadas por Compaoré et al. (2008), evidenciam a praticidade e aplicabilidade da ferramenta, tais como: (1) o algoritmo se baseia fisicamente em imagens de satélite e necessita poucos dados meteorológicos; (2) pode ser aplicado para diferentes sensores além dos Landsat ETM+, TM e OLI, como por exemplo o MODIS (Moderate Resolution Imaging Spectroradiometer) e o AVHRR (Advanced Very High Resolution Radiometer); (3) utiliza uma vasta quantidade de variáveis ambientais; e (4) permite a aplicabilidade do modelo em áreas extensas.

Para a obtenção do balanço da energia superficial, que é o objetivo principal do SEBAL, são implementadas trinta e quatro etapas em seu processamento, gerando informações como emissividade, temperatura da superfície, albedo da atmosfera, albedo de superfície, índices de vegetação como NDVI, SAVI e EVI, entre outros (BASTIAANSSEN, 1995; MOREIRA, 2014). Como o objetivo (ii) deste trabalho é identificar a formação do fenômeno de ICU, são implementadas algumas etapas, de modo a apresentar o modelo não apenas para o seu objetivo final para o qual foi desenvolvido (balanço da energia superficial), mas também para obtenção e extração de resultados oriundos de etapas intermediárias. Tais etapas são descritas no item 3.2.

\subsection{Métodos}

Para o processamento das imagens foi utilizado o software livre de sistema de informação geográfica QGIS, onde foi feita a modelagem das etapas adotas pelo modelo SEBAL. No diagrama de blocos da Figura 2 estão representadas as etapas para o desenvolvimento deste estudo. Onde, a partir das imagens de satélites representadas por números digitais (ND) é feito o processo de calibração para obtenção das reflectâncias espectrais para cada banda da imagem, o índice de vegetação (NDVI) e a temperatura da superfície são calculados utilizando as reflectâncias obtidas. Por fim, foi analisada a correlação entre o NDVI e a temperatura da superfície. A seguir cada etapa será detalhada de acordo com suas respectivas equações e coeficientes. 
Figura 2 - Diagrama de blocos das etapas utilizadas no processamento das imagens.

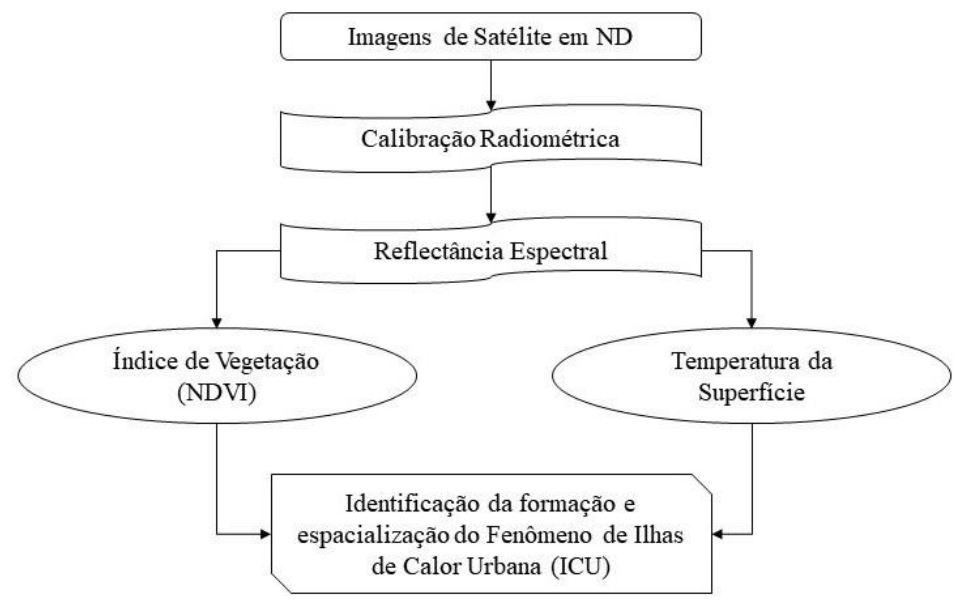

Fonte: Os autores (2021).

\subsubsection{CALIBRAÇÃO RADIOMÉTRICA E REFLECTÂNCIA ESPECTRAL}

A calibração Radiométrica consiste na transformação do número digital (ND) para cada pixel da imagem, em radiância espectral monocromática $\left(L_{\lambda i}\right)$; onde a radiância representa a energia solar refletida pelo alvo terrestre, com relação a unidade de área, tempo e inclinação angular, para as bandas 3 (vermelho), 4 (infravermelho próximo) e 6 (infravermelho termal), quando se refere ao satélite Landsat 5. A radiância espectral foi obtida pela Eq. (1) (MARKHAM; BARKER, 1987):

$$
L_{\lambda i}=a_{i}+\frac{b_{i}-a_{i}}{255} \times N D
$$

em que $a_{i}$ e $b_{i}$ são as radiâncias mínimas e máximas (Tabela 2), ND é o nível de cinza do pixel, e $i$ representa as bandas 3, 4 e 6 do TM Landsat 5. Para as imagens do Landsat 8 só se faz necessário a calibração radiométrica da banda 10 (infravermelho termal) através da Eq. (2) (SILVA et al., 2016):

$$
L_{\lambda}=M_{L} * N D+A_{L}
$$

onde $M_{L}$ é fator de escala multiplicativo da radiação para a banda e $A_{L}$ é o fator de escala aditivo da radiação para cada banda, ambos disponíveis no arquivo metadados da imagem.

Tabela 2 - Coeficientes de calibração do TM-Landsat 5 para a data 28/09/1989: (a) mínimo, (b) máximo.

\begin{tabular}{c|c|c}
\hline Bandas & $\mathbf{a}\left(\mathbf{W} / \mathbf{m}^{\mathbf{2}} \boldsymbol{\mu} / \mathbf{m}^{\mathbf{1}}\right)$ & $\mathbf{b}\left(\mathbf{W} / \mathbf{m}^{\mathbf{2}} \boldsymbol{\mu} / \mathbf{m}^{\mathbf{1}}\right)$ \\
\hline 3 (Vermelho) & $-1,170$ & 204,300 \\
4 (IV - Próximo) & $-1,510$ & 206,200 \\
6 (IV - Termal) & 1,238 & 15,303 \\
\hline
\end{tabular}

Fonte: Adaptada de Chander; Markham e Barsi (2007).

A reflectância monocromática de cada banda $\left(\rho_{\lambda i}\right)$ representa a razão entre o fluxo de radiação refletida por cada banda e o fluxo de radiação incidente, sendo determinada pela Eq. (3) para o Landsat 5 e pela Eq. (4) para o Landsat 8 (BASTIAANSSEN, 1995; ALLEN; TASUMI; TEREZZA, 2002; SILVA et al., 2016):

$$
\begin{aligned}
\rho_{\lambda i} & =\frac{\pi \times L_{\lambda i}}{k_{\lambda i} \times \operatorname{Cos} Z \times d}, \\
\rho_{\lambda i} & =\frac{M_{\rho} * N D+A_{L}}{\operatorname{Cos} Z *\left(\frac{1}{d^{2}}\right)},
\end{aligned}
$$

em que: $L_{\lambda i}$ é a radiância espectral de cada banda, que foi determinada na etapa anterior; $k_{\lambda i}$ é a irradiação solar espectral, de cada banda, no topo da atmosfera; $Z$ é o ângulo de elevação do sol; d é inverso do quadrado 
da distância relativa Terra-Sol e a distância Terra-Sol, em dado dia do ano; $M_{p}$ é fator de escala multiplicativo da reflectância para a cada banda, todos esses dados foram obtidos no arquivo de metadados da imagem.

Através do uso dos valores de reflectância é possível gerar diversos índices, dos quais o foco desta pesquisa são: o índice de vegetação de diferença normalizada (NDVI) e na obtenção da temperatura de superfície.

\subsection{2 ÍNDICE DE VEGETAÇÃO DE DIFERENÇA NORMALIZADA (NDVI)}

O NDVI é um dos parâmetros que destaca a vegetação, por ele ser determinado através da relação entre a absorção da radiação espectral na banda do vermelho pela clorofila presente nas células vegetais e a relação com a reflectância das folhas na região do infravermelho próximo (PUREVDORJ et al., 1998) conforme a Eq. (5) (TURCKER et al., 1986):

$$
N D V I=\frac{\rho_{I V}-\rho_{V}}{\rho_{I V}+\rho_{V}}
$$

onde: $\rho_{I V}$ é a reflectância da banda 4 para o Landsat 5 e 5 para o Landsat 8, e $\rho_{V}$ é a reflectância da banda 3 para o Landsat 5 e 4 para o Landsat 8. Segundo Viganó et al. (2011), o índice varia de -1 a +1 em que as superfícies de água ou nuvem são representadas pelos valores negativos, os índices próximos de zero indicam superfície não vegetada ou solo exposto.

A metodologia utilizada para analisar a espacialização do uso do solo pelo NDVI foi a adotada por Bezerra, Moraes e Soares (2018), onde são utilizadas 5 classes temáticas com relação ao valor do índice de vegetação encontrado, identificadas na Tabela 3. Os autores interpretaram os valores de 0,6 a 0,8 como sendo vegetação densa, já para uma vegetação média os valores são de 0,4 a 0,6 , e para baixa vegetação nos valores de 0,2 a 0,4 , a classe de solo exposto pode ser classificada entre os valores de 0 a 0,2 por fim, a faixa que representa a presença de água contém os valores negativos da classificação.

Tabela 3 - Classes do NDVI para uso e ocupação do solo.

\begin{tabular}{c|c}
\hline Classes temáticas & Intervalo NDVI \\
\hline Água & 00 \\
Solo exposto & 0 a 0,2 \\
Vegetação baixa & 0,2 a 0,4 \\
Vegetação média & 0,4 a 0,6 \\
Vegetação densa & 0,6 a 0,8 \\
\hline
\end{tabular}

Fonte: Adaptada de Bezerra, Moraes e Soares (2018).

\subsubsection{TEMPERATURA DE SUPERFICIE}

A Temperatura de Superfície ( $T s$ ) é determinada a partir da utilização da radiância espectral da banda termal do sensor em questão e da emissividade $\left(\varepsilon_{N B}\right)$, que é a razão entre a energia emitida pela superfície de uma determinada matéria e a energia emitida pelo corpo negro na mesma temperatura (BASTIAANSSEN, 1995; MATOS et al., 2015; MATOS; CANDEIAS; AZEVEDO, 2016). A Eq. (6) representa a temperatura de superfície e é dada por:

$$
T_{s}=\frac{K_{2}}{\ln \left(\frac{\varepsilon_{N B} \times K_{1}}{L_{\lambda}}+1\right)}
$$

onde $K 1$ e $K 2$ são constantes de calibração da banda termal, onde para o Landsat 5 correspondem a 607,76 $W m^{-2} s r^{-1} \mu m^{-1}$ e $1260,56 \mathrm{~K}$, respectivamente; já para o Landsat 8 as constantes de calibração estão disponibilizadas no arquivo metadados.

Para determinação da emissividade da banda termal $\left(\varepsilon_{N B}\right)$ de cada pixel, calculada em função do IAF e do NDVI através da Eq. (6) em que os pixels com IAF $\geq 3$ foi adotado um valor de $\varepsilon_{N B}=0,98$ e para corpos 
d'água (NDVI <0) a $\varepsilon_{N B}=0,99$, ou para NDVI $>0$ e IAF $<3$ a emissividade é obtida através da Eq. (7) (ALLEN; TASUMI; TEREZZA, 2002):

$$
\varepsilon_{N B}=0.97+0.0033 \times I A F,
$$

onde IAF é o Índice de Área Foliar, um indicador de biomassa obtido para cada pixel; tal índice é definido pela razão da área foliar da vegetação por unidade de área utilizada por ela, sendo determinado empiricamente pela Eq. (8) (ALLEN; TASUMI; TEREZZA, 2002):

$$
I A F=-\frac{\ln \left(\frac{0,69-S A V I}{0,59}\right)}{0,91}
$$

O SAVI (Soil Adjusted Vegetation Index - índice de Vegetação Ajustada para o efeito do Solo) é um indicador de vegetação que objetiva diminuir os efeitos do "backgroud" do solo, segundo Huete (1988), através da Eq. (9):

$$
S A V I=\frac{(1+L) \times\left(\rho_{I V}-\rho_{V}\right)}{\left(L+\rho_{I V}+\rho_{V}\right)}
$$

onde $L$ é uma constante que depende do tipo de solo, em que o valor mais utilizado é o 0,5 (MOREIRA, 2009; SANTOS, 2011).

\subsubsection{CORRELAÇÃO ENTRE NDVI E TEMPERATURA DE SUPERFÍCIE}

Para análise da correlação entre os dois parâmetros estudados, temperatura da superfície e NDVI, foi gerada, de forma aleatória, uma malha de 10.000 pontos que atendesse toda a área estudada possibilitando a extração dos valores das imagens raster (Temperatura da Superfície e NDVI). Extraído os valores dos dois parâmetros foi calculado o Coeficiente de Variação (CV) com o objetivo de identificar a homogeneidade das amostras, o intuito desta etapa é identificar se as variáveis são ou não paramétricas, e assim aplicar o melhor método de correlação. O prosseguimento desta etapa se deu aplicando o método de correlação que atendesse as particularidades dos dados; coeficiente correlação de Pearson, caso os dados apresentassem uma relação linear, ou coeficiente de correlação de postos Spearman, se as amostras tiverem ou não uma relação linear. O objetivo desta análise é observar qual a intensidade que existe entre a relação das duas variáveis que são abordadas neste trabalho, em que o coeficiente de correlação varia de -1 a 1 . O sinal indica a direção do relacionamento entre as variáveis, o coeficiente negativo indica que a correlação é inversa, à medida que um dos parâmetros analisados aumenta o outro diminui (FIGUEIREDO FILHO; SILVA JÚNIOR, 2009).

\section{RESULTADOS E DISCUSSÃO}

\subsection{Ilhas de Calor}

A Figura 3 apresenta os resultados para as cartas temáticas obtidas para a Temperatura da Superfície entre os anos de 1989 e 2019. De forma geral, as áreas que apresentam valores mais elevados podem ser identificadas como as áreas mais urbanizadas da cidade nas diferentes épocas abordadas. É possível perceber um aumento em área da temperatura de superfície quando são comparados os anos de 1989 (Figura 3a) e 2019 (Figura 3b). Os valores máximos para temperatura de superfície foram de $36,68{ }^{\circ} \mathrm{C}$ para 2019 e $31,98{ }^{\circ} \mathrm{C}$ para 1989, ambos encontrados para a área onde está localizado o Aeroporto dos Guararapes, destacada pelo polígono vermelho na Figura 3. 
Figura 3 - Cartas temáticas de Temperatura da Superfície $\left({ }^{\circ} \mathrm{C}\right)$ para os anos de 1989 (a) e 2019 (b).

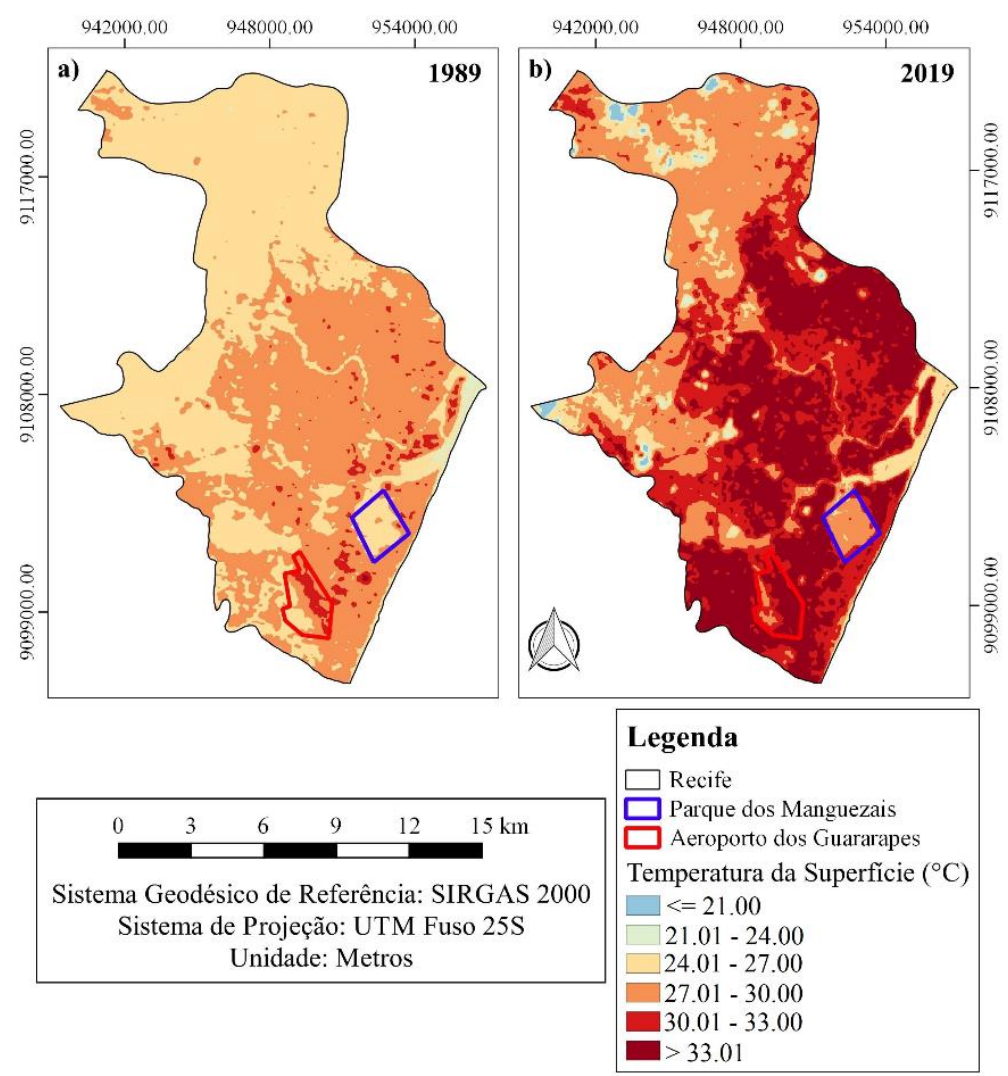

Fonte: Os autores (2021).

A análise espacial da carta de temperatura para o ano de 1989 (Figura 3a) permite identificar a predominância da classe de temperaturas entre $24.01-27.00\left({ }^{\circ} \mathrm{C}\right)$, nas áreas menos populosas da cidade do Recife e que apresentam algumas reservas florestais, e $27.01-30.00\left({ }^{\circ} \mathrm{C}\right)$, que representa a área urbanizada da cidade. As temperaturas menores que $21^{\circ} \mathrm{C}$ não são encontradas para este ano, já as da classe entre 18.01 $-21.00{ }^{\circ} \mathrm{C}$ são observadas como sendo a presença de água, sendo elas o rio Capibaribe e o porto do Recife.

De modo constante, para o ano de 2019 (Figura 3b), a classe que representa as áreas urbanizadas passa a ter temperaturas acima de $33.01{ }^{\circ} \mathrm{C}$, valores elevados de temperatura também foram encontrados, através de medições em estações, por Nóbrega, Santos e Moreira (2016) quando analisados os principais bairro da cidade. As áreas de preservação, que antes apresentavam temperaturas entre $24.01-27.00\left({ }^{\circ} \mathrm{C}\right)$, sofreram um aumento para a classe de $27.01-30.00\left({ }^{\circ} \mathrm{C}\right)$. Foi mantido a temperatura apresentada em 1989 apenas para as áreas na presença de água. As áreas que apresentam temperaturas menores que $24{ }^{\circ} \mathrm{C}$ podem ser interpretadas, em sua maioria, como presença de sombra na imagem.

A Figura 4 traz em formato de gráfico de barras a quantificação, em termos de área $\left(\mathrm{km}^{2}\right)$, das classes obtidas no mapa de Temperatura da Superfície (Fig. 3) para os anos estudados. Os resultados indicam que a classe que sofreu a maior variação com relação aos 6 intervalos estudados foi a que contém temperaturas acima de $33.01\left({ }^{\circ} \mathrm{C}\right)$. Para o ano de 1989 não houve aumento percentual significativo de área para a temperatura. Em 2005 e 2013 foram apresentadas áreas pouco expressivas, por outro lado, os anos de 1994, 2010 e 2019 demonstraram um padrão de crescimento onde a porcentagem de área dobrou. Em se tratando de diminuição de área, quando analisados os anos extremos da série temporal (1989 e 2019), as classes mais afetadas foram as de temperaturas mais amenas $\left(24.01^{\circ}-27.00^{\circ}\right.$ e $\left.27.01^{\circ}-30.00^{\circ}\right)$ onde a diminuição, em termos de porcentagem de área, foi de $43,96 \%$ e $14,29 \%$, respectivamente. O comportamento quanto a temperaturas mais amenas para os anos de 2005 e 2013 podem estar relacionados com a data de aquisição das imagens, pois ambas foram obtidas em meses chuvosos. 
Figura 4 - Evolução das Áreas $\left(\mathrm{km}^{2}\right)$ com relação a Temperatura da Superfície, em porcentagem.

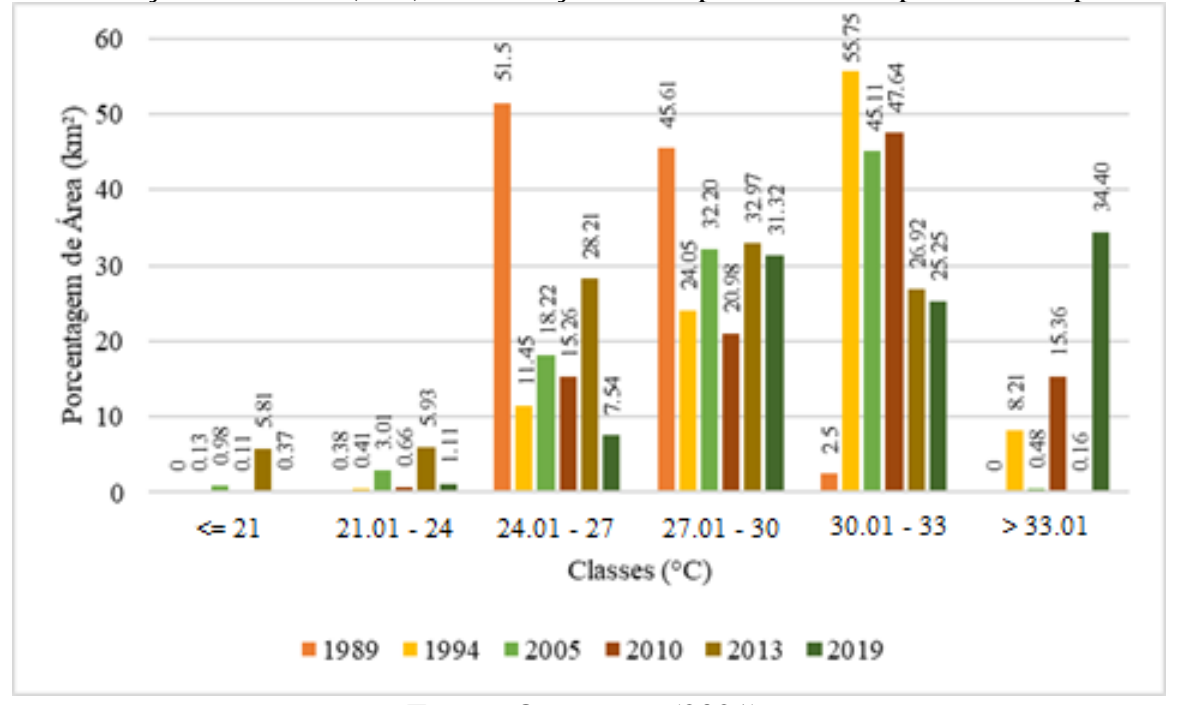

Fonte: Os autores (2021).

Os resultados obtidos por Moreira e Galvíncio (2007) reafirmam os valores de temperatura encontrados neste estudo, onde as áreas de temperaturas mais elevadas são encontradas na região do Aeroporto com temperaturas superiores a $33.01{ }^{\circ} \mathrm{C}$, e áreas com temperaturas mais baixas, entre $24.01-27.00\left({ }^{\circ} \mathrm{C}\right)$ podem ser encontradas em áreas de preservação ambiental como é o caso do Parque dos Manguezais, área destacada pelo polígono azul na Figura 3. Sendo assim, a região do Aeroporto pode ser classificada como ilha de calor e a área do Parque dos Manguezais pode ser classificada como ilha de frescor, tendo em vista que a região ao redor do parque sofreu um aumento de $6^{\circ} \mathrm{C}$ no intervalo de 30 anos enquanto o próprio parque sofreu uma alteração de $3^{\circ} \mathrm{C}$.

\subsection{NDVI}

A Figura 5 apresenta as cartas temáticas geradas para o NDVI através da comparação entre 1989 e 2019. Os resultados indicam o crescimento das áreas classificadas como solo exposto $(0-0,2)$, com ênfase para esta classe em 2019. É possível interpretar que houve a supressão de áreas vegetadas no extremo sul e no centro da cidade; a identificação clara do Rio Capibaribe só se faz presente no mapa de 1989 (Figura 5a), podendo ter causas associadas à proximidade das áreas construídas e até a poluição consequente da expansão urbana comparada com 2019 (Figura 5b).

Analisando o mapa de NDVI para o ano de 2019 (Figura 5b) é possível perceber o crescimento urbano que ocorreu quando comparado com 1989 (Figura 5a), sendo assim intensificado a transformação das superfícies que antes eram vegetadas e passando a ser impermeabilizadas, como é o caso da feição identificada em rosa na Figura 5a e b que representa uma das maiores avenidas em linha reta do país, denominada de Avenida Caxangá. 
Figura 5 - Carta temática de NDVI para os anos de 1989 (a) e 2019 (b).

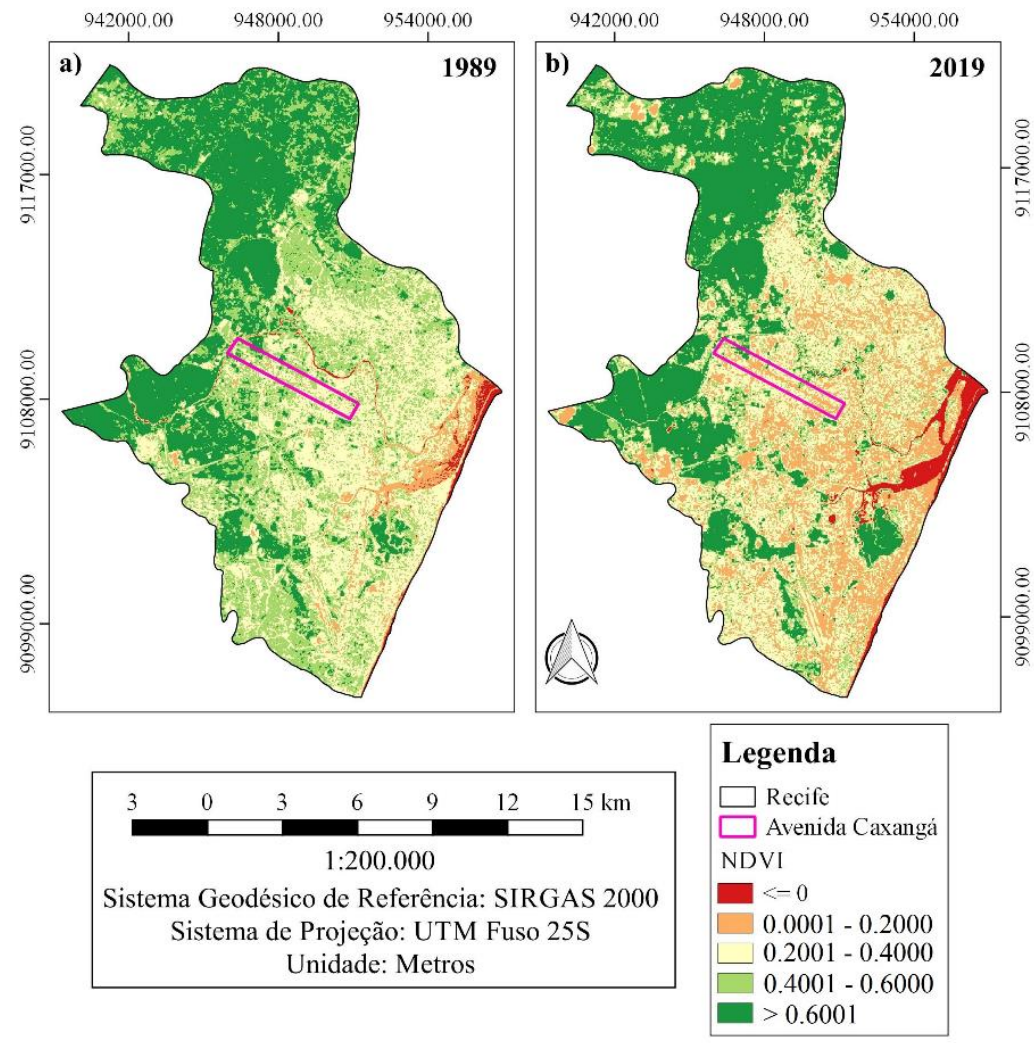

Fonte: Os autores (2021).

A Figura 6 apresenta a distribuição, em percentual de área $\left(\mathrm{km}^{2}\right)$, das classes do NDVI para a cidade do Recife nos anos estudados. Analisando os percentuais de área é possível identificar a diminuição anual que ocorreu quando se trata da classe de vegetação média, onde sua área praticamente foi reduzida pela metade quando explorados os anos extremos da série. Para o ano de 1989 é possível identificar que havia grandes áreas classificadas como presença de vegetação chegando a ocupar mais de $90 \%$ da área total da cidade, onde 30,85\% foi classificada como vegetação baixa, $31,45 \%$ como vegetação média e 32,04\% como vegetação densa, a classe de solo exposto contabilizou apenas 4,59\%. Quando observada a classe de vegetação densa foi identificado um decréscimo em relação ao ano anterior à 2010, detectando uma variabilidade alterada até chegar em 2019 apresentando um quantitativo de área semelhante ao apresentado no ano de 1989.

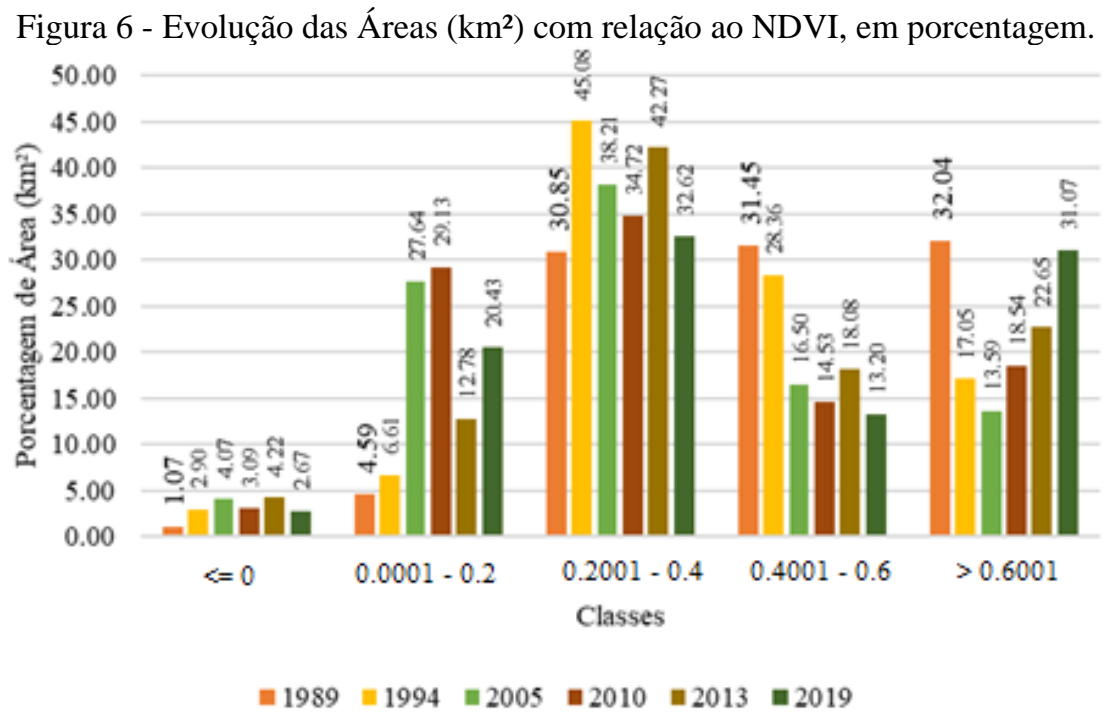

Fonte: Os autores (2021).

\subsection{Variação temporal do NDVI e Temperatura da superfície}


A variação dos dois parâmetros, NDVI e Temperatura da superfície, durante o período de 30 anos, foi processada através da série temporal contendo quatros anos distintos, além dos extremos abordados anteriormente. Os resultados obtidos são apresentados na Figura 7, os quais apresentam os anos de 1989, 1994, 2005, 2010, 2013 e 2019 (Figura 7a, b, c, d, e, f, respectivamente), juntamente com o mesmo perfil longitudinal e valores para cada ano. O comportamento do NDVI e da Temperatura da superfície apresentam um comportamento similar para os anos estudados. A relação dos dois é considerada inversa sendo possível identificar o aumento gradativo da temperatura com o passar dos anos e o processo de transformação da cobertura vegetal para a mesma região.

Observando o perfil selecionado é plausível identificar o processo de formação das ilhas de calor no decorrer dos anos. Para os três primeiros (Figura 7a, b, c) houve a presença deste fenômeno mais ao sul do perfil traçado, onde está localizado o Aeroporto da cidade, tal fenômeno pode ser justificado através da alteração do uso do solo como visto pelo aumento das áreas em laranja $(0.0001-0,2)$ nos dados do NDVI. O processo das ilhas de calor sofre uma alteração, quando analisados os anos posteriores (Figura $7 \mathrm{~d}$, f) onde fica difícil identificar ilhas de temperaturas elevadas quando todo seu entorno também está na mesma faixa de temperatura, passando a ser possível detectar as ilhas de frescor que podem ser localizadas mais ao norte do perfil, região onde está situado o Parque dos Manguezais.

É possível perceber através da Figura 7 que existem alguns comportamentos padrões e que chamam a atenção conforme sua variabilidade, como é o caso da relação de temperatura apresentada na Figura $7 \mathrm{~b}$ e $7 \mathrm{c}$ onde era esperado que houvesse um aumento de áreas com temperaturas mais elevadas levando em consideração que o NDVI aumentou, porém como as imagens foram obtidas para períodos de precipitação distintos (Tabela 1), onde o critério de escolha das imagens foi com relação a presença de nuvens na mesma bem como sua disponibilidade. Destaca-se ainda que em 2010 (Figura 7d) os valores de temperatura são bastante elevados apresentando baixos valores de NDVI e em 2013 (Figura 7e) foram detectadas temperaturas mais amenas e valores altos de NDVI, ou seja, confirmando a hipótese de padrão esperado, onde à medida em que um fator aumenta o outro diminui.

Figura 7 - Recorte do perfil longitudinal para os dados de NDVI e Temperatura da Superfície ( $\left.{ }^{\circ} \mathrm{C}\right)$; são apresentados os resultados para os anos, em a) 1989, b) 1994, c) 2005, d) 2010, e) 2013 e f) 2019.

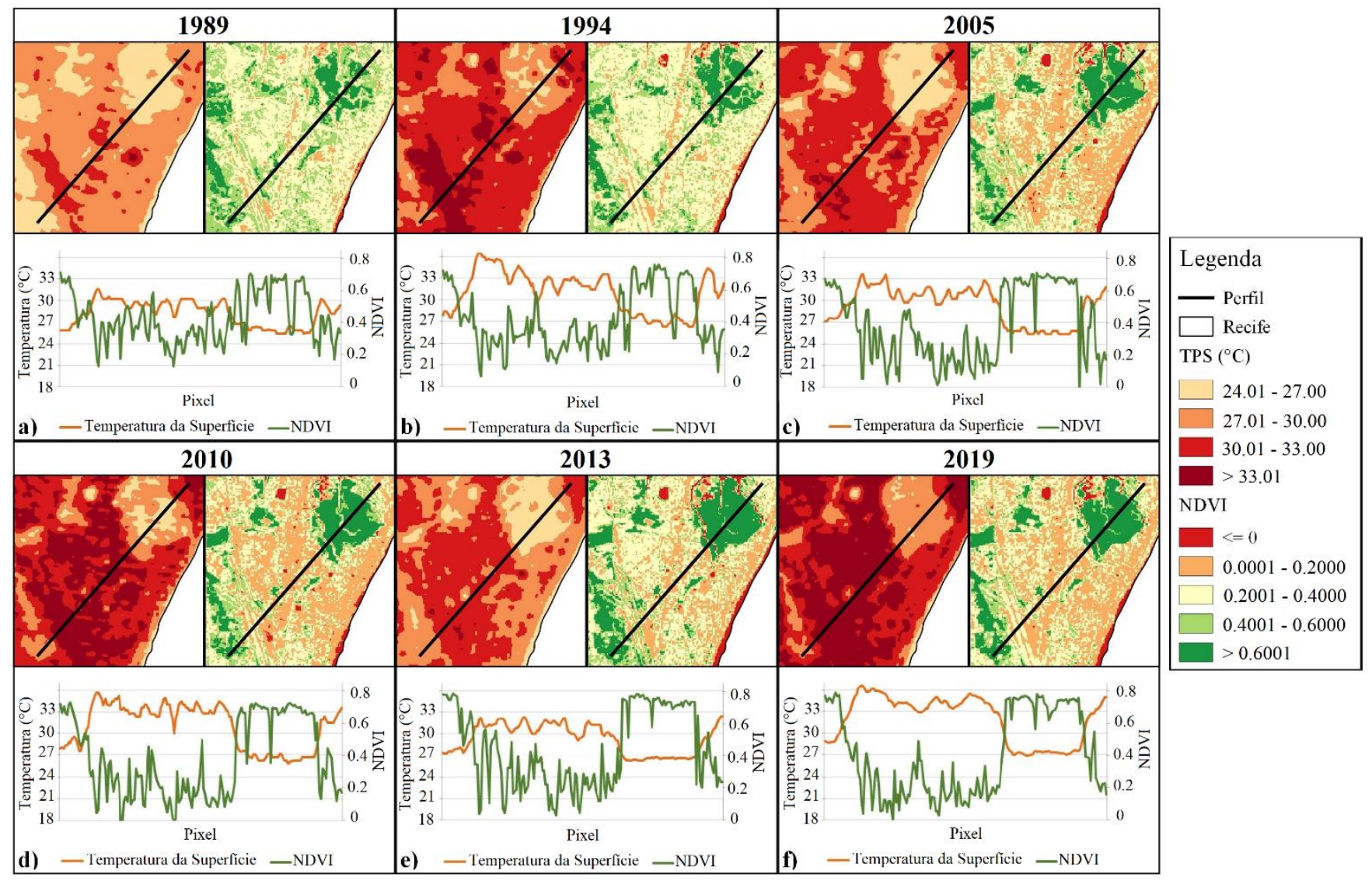

Fonte: Os autores (2021). 
Oliveira, Ganem e Baptista (2017), em um estudo sobre a relação do sequestro do carbono e a temperatura da superfície aplicado a grandes metrópoles como São Paulo, Rio de Janeiro, Belo Horizonte e Brasília, interpretaram a correlação que existe entre temperaturas elevadas e a ausência de vegetação. Tal afirmativa também é aplicável ao estudo de caso da cidade do Recife, onde as áreas classificadas como vegetação densa $(>0,6001)$ apresentaram temperaturas mais amenas podendo estas serem identificadas como ilhas de frescor.

A partir de uma análise com todos os resultados sobrepostos (Figura 8), apresentados por meio de um transecto (Figura 8a), é possível observar a variação da temperatura em relação aos anos estudados com um acréscimo quase que constante de $2{ }^{\circ} \mathrm{C}$ em todo o perfil (Figura 8c), mantendo uma variação menor que $1{ }^{\circ} \mathrm{C}$ nas áreas onde os valores do NDVI (Figura 8b) são os mais altos (no ponto A e área mais próxima ao ponto B). Ao longo de todo o transecto é notória a relação inversa que existe entre as duas variáveis, resultados semelhantes foram encontrados por Oliveira, Ganem e Baptista (2017).

Figura 8 - Perfil longitudinal na cidade do Recife, onde em a) temos a representação do perfil obtido, em b) o gráfico com a série obtida para valores de NDVI, e em c) gráfico da Temperatura da superfície $\left({ }^{\circ} \mathrm{C}\right)$ obtidas para todos os anos abordados.
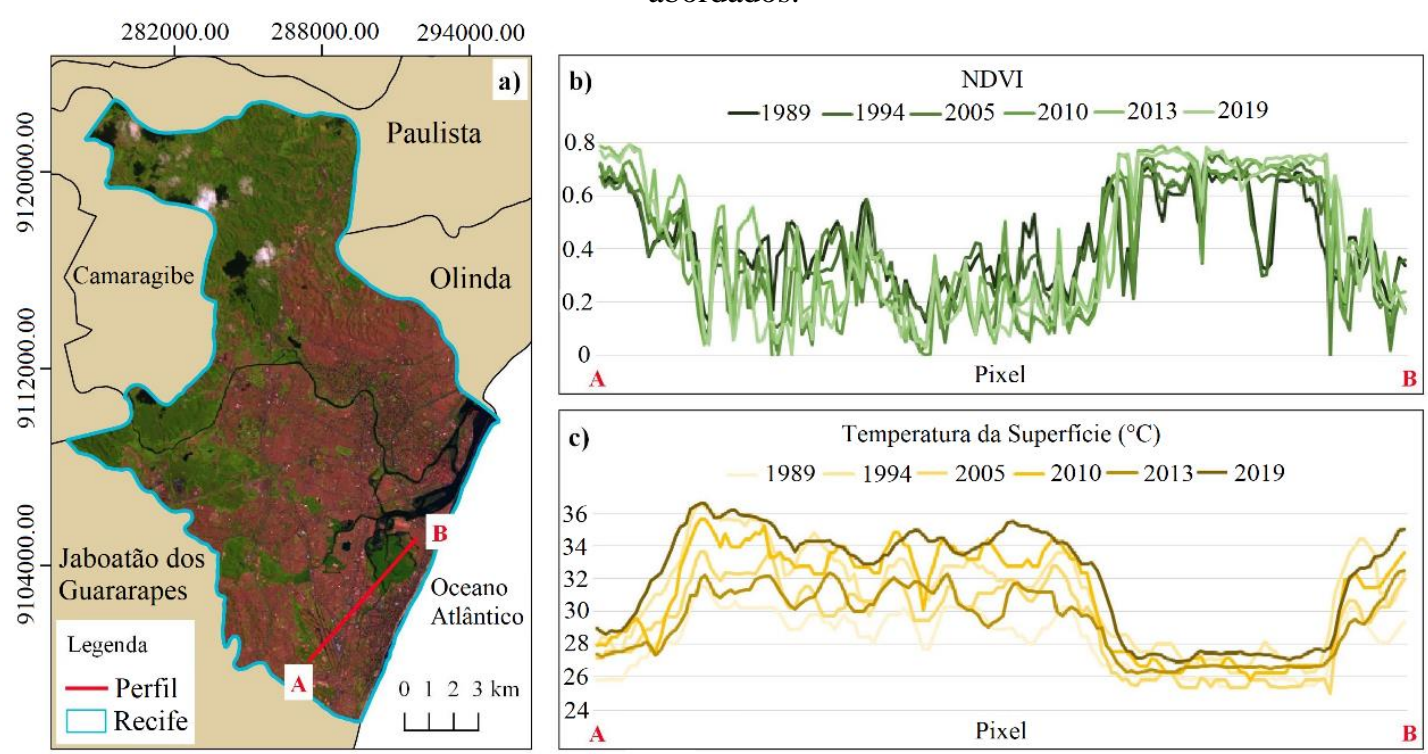

Sistema Geodésico de Referência: SIRGAS 2000 Sistema de Projeção: UTM Fuso 25S Unidade: Metros

Fonte: Os autores (2021).

\subsection{Correlação entre NDVI e temperatura superficial}

De acordo com a metodologia (item 3.2.4) a análise estatística dos dados para os anos extremos estudados (1989 e 2019), fez uso da correlação de Spearman ( $\rho)$. A análise bilateral foi testada em nível de significância de $1 \%$, adotando como hipótese nula o pressuposto que o resultado estatístico da correlação foi obtido por coincidência devido a flutuações probabilísticas, e sua hipótese alternativa considera uma real similaridade. A correlação obtida para o ano 1989 foi de $(\rho)=-0,72$ representando uma correlação forte negativa; o ano de 2019 apresentou uma correlação de $(\rho)=-0,59$ sendo ela moderada negativa, ambas correlações obtiveram um p-valor igual a zero, ou seja menor que o nível de significância adotado no estudo, assim rejeitando a hipótese nula e aceitando a hipótese alternativa, ou seja, afirmando que existe uma real similaridade na correlação. A variação no valor de correlação obtido para o ano de 2019, quando comparado ao ano de 1989, pode ser interpretada pela presença de fatores externos a este trabalho. Zhang et al. (2020), avaliando a correlação e os efeitos de defasagem entre o NDVI e fatores climáticos e antrópicos em uma área da China, encontraram uma correlação negativa entre o índice de vegetação e a temperatura, indicando que o aumento da temperatura impactou negativamente na dinâmica da vegetação em conjunto com fatores antrópicos como por exemplo, o aumento das construções. Em um estudo feito por Lotufo et al. (2020) para verificar a influência das queimadas na resposta espectral do NDVI, em um parque estadual no Mato Grosso, 
também foram obtidos coeficientes de correlação negativos quando avaliados com a Temperatura da Superfície, corroborando com os dados estatísticos encontrados no presente estudo.

\section{CONCLUSÃO}

Este estudo fez uso de técnicas de processamento digital de imagens aplicadas nas imagens dos satélites Landsat 5 e 8 com a finalidade de se obter a variabilidade dos parâmetros NDVI e temperatura de superfície. O conjunto de dados abrangeu um intervalo de 30 anos, de 1989 a 2019, considerando a cidade do Recife como estudo de caso. A abordagem estatística foi feita utilizando a correlação de Spearman (modelo de correlação não-paramétrico). As principais conclusões encontradas foram:

a) Com relação aos extremos do período abordado, o ano de 2019 apresentou as temperaturas mais elevadas, quando comparadas ao ano de 1989, chegando a alcançar valores próximos a $37^{\circ} \mathrm{C}$. Em contrapartida, para 1989 os valores mais altos de temperatura foram próximos de $32{ }^{\circ} \mathrm{C}$. Em termos de variabilidade espacial $\mathrm{em} \mathrm{km}^{2}$, a cidade do Recife sofreu um crescimento de $34 \%$ nas temperaturas acima de $33.01^{\circ} \mathrm{C}$, vindo a diminuir em aproximadamente $44 \%$ os locais que antes possuíam temperaturas mais amenas como as do grupo entre $24.01{ }^{\circ} \mathrm{C}$ a 27 ${ }^{\circ} \mathrm{C}$.

b) Para a classe de vegetação densa os valores obtidos de NDVI se comportaram de forma parecida, não passando de $1 \%$ entre os anos extremos nas áreas consideradas de preservação ambiental ou propriedades situadas na parte menos urbanizada da cidade. A classe que mais sofreu variação foi a representada pelos valores de 0.0001 - 0,2 (solo exposto), onde a porcentagem de área foi quadruplicada com relação aos anos extremos (1989 e 2019), saltando em torno de $5 \%$ para $21 \%$. Em contrapartida, a classe de vegetação média sofreu uma diminuição de $18 \%$.

c) Através da análise estatística e perfis adotados foi possível afirmar que houve uma correlação inversa entre os parâmetros considerados (NDVI e Temperatura da Superfície), onde os coeficientes obtidos foram de intensidade forte negativa $(\rho=-0,72)$ e moderada negativa $(\rho=$ -0,59) para os anos de 1989 e 2019, respectivamente.

d) Através da série temporal utilizada foi possível detectar e verificar a variabilidade tanto das Ilhas de Calor Urbanas quanto das Ilhas de Frescor. Uma das dificuldades encontradas foi em identificar as bordas das ICU em áreas mais densas da cidade do Recife. Por fim, destaca-se que o aumento da temperatura superficial durante os 30 anos estudados foi considerado alto.

\section{Agradecimentos}

O primeiro autor agradece a bolsa de mestrado apoiada pelo projeto 23076.033077/201858/FADE/UFPE/Prefeitura de Caruaru, o segundo autor agradece o apoio ao projeto 310452/2018-0/PQ/CNPq e o último autor agradece a bolsa de mestrado apoiada pela CAPES.

\section{Contribuição dos Autores}

Definição do problema de pesquisa (R. Mikosz), Revisão da literatura (R. Vila Nova e F. Lima), Definição dos procedimentos metodológicos (R. Mikosz), Coleta de dados (R. Vila Nova e F. Lima), Processamento de dados (R. Vila Nova), Análise e interpretação de dados (R. Vila Nova, R. Mikosz e F. Lima), Redação de manuscritos (R. Vila Nova, R. Mikosz e F. Lima).

\section{Conflitos de Interesse}

Os autores declaram que não há conflitos de interesse. 


\section{Referências}

ALLEN, R.G., TASUMI, M; TEREZZA. R. SEBAL (Surface Energy Balance Algorithms for Land) Advanced Training and User Manual - Idaho Implementation, version 1.0, 2002.

AMORIM, M. C. DE C. T.; DUBREUIL, V.; CARDOSO, R. DOS S. Modelagem espacial da ilha de calor urbana em Presidente Prudente (SP) - Brasil. Revista Brasileira de Climatologia, v. 16, p. 29-45, Jan/Jul 2015. ISSN. 2237-8642.

ARNFIELD, A. J. Two decades of urban climate research: A review of turbulence, exchanges of energy and water, and the urban heat island. International Journal of Climatology, v. 23, n. 1, p. 1-26, Jan 2003. DOI. 10.1002/joc.859.

ARYA, S. P. Air Pollution Meteorology and Dispersion, 2 ed. San Diego, California, USA: Academic Press, 2001.

BARROS, H. R.; LOMBARDO, M. A. A ilha de calor urbana e o uso e cobertura do solo em São Paulo-SP. Geousp - Espaço e Tempo (Online), v. 20, n. 1, p. 160-177, Jan/ Apr 2016. ISSN. 2179-0892.

BASTIAANSSEN, W. Regionalization of surface flux densities and moisture indicators in composite terrain. Netherlands: Wageningen, 1995.

BEZERRA, P. E. S.; MORAES, E. T. I. DE; SOARES, I. R. DA C. Análise da Temperatura de Superfície edo Índice de Vegetação no Município de Belém na Identificação das Ilhas de Calor. Revista Brasileira de Cartografia, v. 70, n. 3, p. 803-818, Out 2018. DOI. https://doi.org/10.14393/rbcv70n3-45701.

CHANDER, G.; MARKHAM, B. L.; BARSI, J. A. Revised Landsat-5 Thematic Mapper Radiometric Calibration. IEEE GEOSCIENCE AND REMOTE SENSING LETTERS, v. 4, n. 3, p. 490-494, Jul 2007. DOI. 10.1109/LGRS.2007.898285.

CHEN, X. L.; ZHAO, H. M.; LI, P. X.; YIN, Z. Y. Remote sensing image-based analysis of the relationship between urban heat island and land use/cover changes. Remote Sensing of Environment, v. 104, n. 2, p. 133-146, Sep 2006. DOI. 10.1016/j.rse.2005.11.016.

COMPAORÉ, H.; HENDRICKX, J. M.; HONG, S.; FRIESEN, J.; VAN DE GIESEN, N. C.; RODGERS, C.; SZARZYNSKI, J.; VLEK, P. L. G. Evaporation mapping at two scales using optical imagery in the White Volta Basin, Upper East Ghana. Physics and Chemistry of the Earth, v.33, p.127-140, May 2008. DOI. 10.1016/j.pce.2007.04.021.

COSTA, D. F. DA; SILVA, H. R.; PERES, L. D. F. Identificação de ilhas de calor na área urbana de Ilha Solteira - SP através da utilização de geotecnologias. Eng. Agríc., Jaboticabal, v. 30, n. 5, p. 974-985, Apr 2010. DOI. 10.1590/S0100-69162010000500019.

DANCEY, C. P.; REIDY, J. Estatística Sem Matemática para Psicologia: Usando SPSS para Windows. Porto Alegre, Artmed, 2006.

FIGUEIREDO FILHO, D. B.; SILVA JÚNIOR, J. A. DA. Desvendando os mistérios do coeficiente de correlação de Pearson (r). Revista Política Hoje, v. 18, n. 1, p. 115-146, 2009.

FRANÇA, L. M. DE A.; SANTOS, M. S. DOS; LINS, T. M. P.; PEREIRA, J. A. DOS S.; GALVÍNCIO, J. D. Análise do desconforto térmico causado pela ilha de calor urbana em um bairro do Recife-PE utilizando sensoriamento remoto. In: SIMPÓSIO BRASILEIRO DE SENSORIAMENTO REMOTO - SBSR, 17 , 2015, João Pessoa-PB, Brasil. Anais... São José dos Campos: INPE, 2015. p. 5842-5849.

GALLO, K. P.; TARPLEY, J. D.; MCNAB, A. L.; KARL, T. R. Assessment of urban heat islands: a satellite perspective. Atmospheric Research, v. 37, n. 1-3, p. 37-43, Jul 1995. DOI. 10.1016/01698095(94)00066-M.

GAMARRA, N. L. R.; CORRÊA, M. D. P.; TARGINO, A. C. D. L. Utilização de sensoriamento remoto em análises de albedo e temperatura de superfície em Londrina - PR: contribuições para estudos de ilha de calor urbana. Revista Brasileira de Meteorologia, v. 29, n. 4, p. 537-550, Oct/ Dec 2014. DOI. 10.1590/0102-778620130671. 
HUETE, A. R. A. Soil-Adjusted Vegetation Index (SAVI). Remote Sensing of Environment, v. 25, n. 1, p. 295-309, Aug 1988. DOI. 10.1016/0034-4257(88)90106-X.

IBGE. IBGE divulga as Estimativas de População dos municípios para 2018. 2018.

IMHOFF, M. L.; ZHANG, P.; WOLFE, R. E.; BOUNOUA, L. Remote sensing of the urban heat island effect across biomes in the continental USA. Remote Sensing of Environment, v. 114, p. 504-513, Mar 2010. DOI. 10.1016/j.rse.2009.10.008.

KÖPPEN, W. Sistema Geográfico dos Climas. Notas e Comunicações de Geografia. n. 12, p. 4-29. Tradução Antônio Carlos de Barros Correa, 2004.

LIMA, V.; AMORIM, M. C. DE C. T. A utilização de informações de temperatura da superfície, do NDVI e de temperatura do ar na análise de qualidade ambiental urbana. In: SIMPÓSIO BRASILEIRO DE SENSORIAMENTO REMOTO - SBSR, 15, 2011, Curitiba-PR, Brasil. Anais... São José dos Campos: INPE, 2011. p. 1028-1035.

LIU, L.; ZHANG, Y. Urban heat island analysis using the landsat TM data and ASTER Data: A case study in Hong Kong. Remote Sensing, v. 3, n. 7, p. 1535-1552, Jul 2011. DOI. 10.3390/rs3071535.

LO, C. P.; QUATTROCHI, D. A. Land-use and land-cover change, urban heart island phenomenon, and health implication: A remote sensing approach. Photogrammetric Engineering \& Remote Sensing, v. 69, n. 9, p. 1053-1063, Sep 2003. DOI. 10.14358/PERS.69.9.1053.

LOTUFO, J. B. DA S.; MACHADO, N. G.; TAQUES, L. DE M.; MÜTZENBERG, D. M. DE S.; NETO, N. L.; BIUDES, M. S. Índices Espectrais e Temperatura de Superfície em Áreas Queimadas no Parque Estadual do Araguaia em Mato Grosso. Revista Brasileira de Geografia Física, v. 13, n. 02, p. 648-663, Apr 2020. DOI. 10.26848/rbgf.v13.2.p648-663.

MANLEY, G. On the frequency of snowfall in metropolitan England. Quarterly Journal of the Royal Meteorological Society, v. 84, p. 70-72, Aug 1958. DOI. 10.1002/qj.49708435910.

MARKHAM, B. L.; BAKER, J. L. Thematic mapper bandpass solar exoatmospherical irradiances, Int. Journal of Remote Sensing, v. 8, n. 3, p. 517- 523, Apr 1987. DOI. 10.1080/01431168708948658.

MATOS, R. C. DE M.; CANDEIAS, A. L. B.; AZEVEDO, J. R. G.; HATTERMANN, F. F.; KOCH, H.; KLEINSCHMI, B. Análise multitemporal do albedo, NDVI e temperatura no entorno do reservatório de Itaparica - PE: anos de 1985 e 2010. Revista Brasileira de Cartografia, v. 3, n. 67, p. 545-554, May/ Jun 2015.

MATOS, R. C. DE M.; CANDEIAS, A. L. B.; AZEVEDO, J. R. G. DE. Estimativas do saldo de radiação instantâneo no entorno do reservatório de Itaparica - PE com uso de imagens orbitais. Revista Brasileira de Cartografia, p. 641-654, 2016.

MOREIRA, E. B. M. Variação espacial e multitemporal das temperaturas da superfície na Cidade do Recife. 97 f. Dissertação (Mestrado em Geografia) - Departamento de Ciências Geográficas, Universidade Federal de Pernambuco, Recife, 2009.

MOREIRA, E. B. M. Balanço de energia e evapotranspiração na cidade do Recife-PE por sensoriamento remoto. 155 f. Tese (Doutorado em Geografia) - Departamento de Ciências Geográficas, Universidade Federal de Pernambuco, Recife, 2014.

MOREIRA, E. B. M.; GALVÍNCIO, J. D. Espacialização das temperaturas à superfície na cidade do Recife, utilizando imagens TM-LANNDSAT 7. Revista de Geografia (Recife), v. 24, n. 3, p. 101-115, Sep/ Dec 2007.

MOREIRA, E. B. M.; NÓBREGA, R. S.; SILVA, B. B. DA; RIBEIRO, E. P. O modelo SEBAL para estudos de clima intraurbano: aplicação em Recife, Pernambuco, Brasil. RA'EGA - O Espaço Geográfico em Análise, v. 39, p. 247-265, Apr 2017. DOI. 10.5380/raega.v39i0.45691.

MOREIRA, E. B. M.; NÓBREGA, R. S. Identificação do fenômeno ilhas de calor na área urbana do RecifePE, através do canal infravermelho termal do satélite Landsat 5. In: Simpósio Brasileiro de Sensoriamento Remoto - SBSR, 15, 2011, Curitiba-PR, Brasil. Anais... São José dos Campos: INPE, 2011. p. 0768-0775.

NÓBREGA, R. S.; LEMOS, T. V. DA S. O microclima e o (des)conforto térmico em ambientes abertos na 
cidade do Recife. Revista de Geografia (UFPE), v. 28, n. 1, p. 93-109, Jul 2011.

NÓBREGA, R. S.; SANTOS, P. F. C. DOS; MOREIRA, E. B. M. Variação diurna-noturna das ilhas de calor na cidade do Recife - PE. In: Simpósio Brasileiro de Climatologia Geográfica - SBCG, 12, 2016, GoiâniaGO, Brasil, Anais... ABClima, 2016. p. 1718-1729.

OKE, T. R. City size and the urban heat island. Atmospheric Environment Pergamon Press, v. 7, p. 769779, Aug 1973. DOI. 10.1016/0004-6981(73)90140-6.

OLIVEIRA, M. T. DE; GANEM, K. A.; BAPTISTA, G. M. de M. Análise sazonal da relação entre sequestro de carbono e ilhas de calor urbanas nas metrópoles de São Paulo, Rio de Janeiro, Belo Horizonte E Brasília. Revista Brasileira de Cartografia, v. 69, n. 4, p. 807-825, Apr 2017.

PENG, S.; PIAO, S.; CIAIS, P.; FRIEDLINGSTEIN, P.; OTTLE, C.; BRÉON, F. M.; NAN, H.; ZHOU, L.; MYNENI, R. B. A. Surface urban heat island across 419 global big cities. Environmental Science and Technology, v. 46, n. 2, p. 696-703, Dec 2012. DOI. 10.1021/es2030438.

SECTMA - Secretaria de Ciência Tecnologia e Meio Ambiente. Atlas de bacias hidrográficas de Pernambuco. Recife: SECMA, 2006.

PUREVDORJ, T. S., TATEISHI, R., ISHIYAMA, T., \& HONDA, Y. Relationships between percent vegetation cover and vegetation indices. International Journal of Remote Sensing, v. 19, n. 18, p. 3519-3535, Nov 1998. DOI. 10.1080/014311698213795.

SANTOS, T. O. DOS. Identificação de ilhas de calor em Recife-PE por meio de sensoriamento remoto e dados meteorológicos de superfície. 90 f. Dissertação (Mestrado em Engenharia Agrícola) Departamento de Engenharia Agrícola, Universidade Federal Rural de Pernambuco, Recife, 2011.

SENA, C. A. P.; FRANÇA, J. R. A.; PERES, L. F. Estudo da ilha de calor na região metropolitana do Rio de Janeiro usando dados do MODIS. Anuario do Instituto de Geociencias - UFRJ, v. 37, n. 2, p. 111-122, Dec 2014. DOI. 10.11137/2014_2_111_122.

SILVA, B. B.; BRAGA, A. C.; OLIVEIRA, L. M. M.; MONTENEGRO, S. M. G. L.; BARBOSA JUNIOR, B. Procedures for calculation of the albedo with OLI-Landsat 8 images: Application to the Brazilian semiarid. Revista Brasileira de Engenharia Agrícola e Ambiental, v.20, n.1, p. 3 - 8, Jan 2016. DOI. 10.1590/1807-1929/agriambi.v20n1p3-8.

SOUZA, D. O. DE. Influência da ilha de calor urbana das cidades de Manaus e Belém sobre o microclima local. 219 f. Tese (Doutorado em Meteorologia) - Instituto Nacional de Pesquisas Espaciais, São José dos Campos, 2012.

STATHOPOULOU, M.; CARTALIS, C. Downscaling AVHRR land surface temperatures for improved surface urban heat island intensity estimation. Remote Sensing of Environment, v. 113, n. 12, p. 2592 2605, Dec 2009. DOI. 10.1016/j.rse.2009.07.017.

SUN, C. Y.; BRAZEL, A. J.; CHOW, W. T. L.; HEDQUIST, B. C.; PRASHAD, L. Desert heat island study in winter by mobile transect and remote sensing techniques. Theoretical and Applied Climatology, v. 98, n. 3-4, p. 323-335, Feb 2009. DOI. 10.1007/s00704-009-0120-2.

TEIXEIRA, D. C. F.; AMORIM, M. C. DE C. T.; DUBREUIL, V. Modelagem da ilha de calor urbana para cidade pequena (Rancharia-SP) a partir de imagens do satélite Landsat 7 e de medidas da temperatura do ar. In: Simpósio Brasileiro de Sensoriamento Remoto - SBSR, 17, 2015, João Pessoa-PB, Brasil. Anais... São José dos Campos: INPE, 2015. p. 3181-3188.

TURCKER, C. J.; FUNG, I. Y.; KEELING, C. D.; GAMMON, R. H. Relationship between atmospheric CO2 variations and a satellite-derived vegetation index. Nature, v. 319, p. 195-199, Jan 1986. DOI. 10.1038/319195a0.

VIGANÓ, H. A.; BORGES, E. F.; FRANCA-ROCHA, W. DE J. S. Análise do desempenho dos Índices de Vegetação NDVI e SAVI a partir de imagem Aster. In: Simpósio Brasileiro de Sensoriamento Remoto SBSR, 15, 2011, Curitiba-PR, Brasil. Anais... São José dos Campos: INPE, 2011. p. 1828-1834.

YUAN, F.; BAUER, M. E. Comparison of impervious surface area and normalized difference vegetation index as indicators of surface urban heat island effects in Landsat imagery. Remote Sensing of Environment, 
v. 106, n. 3, p. 375-386, Feb 2007. DOI. 10.1016/j.rse.2006.09.003.

ZHANG, P.; CAI, Y.; YANG, W.; YI, Y.; YANG, Z.; FU, Q. Contributions of climatic and anthropogenic drivers to vegetation dynamics indicated by NDVI in a large dam-reservoir-river system. Journal of Cleaner Production, v. 256, p. 120477, May 2020. DOI. 10.1016/j.jclepro.2020.120477.

\section{Biografia do autor principal}

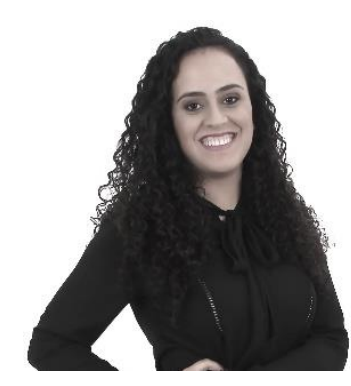

Raquel Arcoverde Vila Nova, natural de Recife-PE é engenheira cartógrafa formada pela Universidade Federal de Pernambuco (UFPE) e Mestranda no Programa de Pós-Graduação em Ciências Geodésicas e Tecnologias da Geoinformação (PPGCGTG), UFPE. Tem atuado nos seguintes temas: mudanças climáticas, cartografia costeira, sensoriamento remoto e recursos hídricos. outros distribuam, remixem, adaptem e criem a partir do seu trabalho, mesmo para fins comerciais, desde que lhe atribuam o devido crédito pela criação original. 